\title{
Usability testing of an online information literacy tutorial
}

Sophie Bury

Joanne Oud

\begin{abstract}
Purpose - Usability testing can play a valuable role in improving the effectiveness of online information literacy instruction, while forming a core component in a wider assessment plan. This article aims to discuss the usability testing of an online information literacy tutorial for freshman undergraduates at Wilfrid Laurier University Library.

Design/methodology/approach - Two librarians, working to fulfill an important mandate of the Library's Information Literacy Task Force, defined goals, created and implemented a modest, though effective, approach to usability assessment.

Findings - The testing provided detailed information on the ease of use of the tutorial, as well as users' satisfaction levels with content and design. These findings informed subsequent revisions and enhancements to the online tutorial.

Originality/value - Student evaluation questionnaires distributed subsequent to the tutorial overhaul indicate the success of usability testing in the development of a more effective learning tool.

Keywords Academic libraries, Assessment, Redesign, Teaching methods, User studies, Internet
\end{abstract}

\section{Introduction}

At Wilfrid Laurier University, librarians applied usability assessment as a key component in the evaluation of an online information literacy tutorial integrated within a number of undergraduate first year Arts courses. A review of the literature resulted in some important and useful findings on effective approaches to usability evaluation. Some articles even shed light on the application of usability testing in a library context. However, the focus inevitably lay on usability testing of library web sites, and not on usability assessment of online library instruction. This article outlines the approach adopted by Wilfrid Laurier University Library in testing usability of an online library tutorial geared at freshmen undergraduates (www.wlu.ca/wwwlib/infolit/tutorial/). While many of the fundamental principles and techniques associated with usability evaluation were adopted, several key differences in approach were necessary to ensure that goals were met and that the method adopted was practical and effective, given the context and problem at hand.

\section{Literature review}

A review of the literature shows clear evidence of a growth in online instruction in the field of information literacy. Many libraries have embraced the advantages of 
web-based tutorials such as the ability to offer instruction on an as-needed basis, the removal of the limitations of the one shot session, and the ability to offer instruction anywhere, any time to both local and distance or off-campus users (Dewald, 1999). A significant amount has been written in the library literature about evaluation of library instruction (Carter, 2002). However, little has been written about the online environment, and next to nothing about usability assessment of online information literacy instruction. Nonetheless, a review of the existing literature on usability evaluation did hold some important insights for librarians at Laurier and the design of effective testing for our online tutorial.

Our first priority as librarians was to learn as much as possible about usability testing. Works of gurus such as Jakob Nielsen (1993, 2000a, 2000b), and Steve Krug (2000) provide detailed information on the definition, goals, rationale, and methodologies of usability assessment. Jakob Nielsen (1993) defines a usable interface as one which is:

- easy to learn;

- efficient to use;

- easy to remember;

- causes few errors; and

- pleasant to use.

The concept of usability has been in existence since the 1980s (Head, 1999). It has its roots in usability engineering, where HCI or human-computer interaction examines how users interact with computer technology and looks at ways of making this interaction effective. Testing was initially applied to software applications and computer interfaces but in time it was recognized that the same concepts could be applied in testing web design including library web sites (Battleson et al., 2001). Web usability testing is typically carried out with the goal of establishing where users become frustrated and where the major trouble spots lie. It should be remembered that usability is multi-faceted and evaluation sets out to determine users' experience of the effectiveness of many aspects of a web site including navigation, labeling, layout, look and feel, language, and accessibility (Gore and Hirsh, 2003).

Much has been written about ways to conduct formal usability testing, which consists of observing and recording users carrying out specific requested tasks. A low tech approach to designing and administering testing is acceptable as long as questions and the process are well designed. Some fundamental guidelines relating to the preparation and execution of formal usability testing are: decide what to test and then design scenarios which will require the user to perform tasks you want to test; write a script for administering the test to ensure consistency; ask the testers to think aloud as they work through the tasks; have a moderator/facilitator who asks questions and a recorder who transcribes what is observed; identify individuals to act as testers who are representative of your target user population; offer some kind of incentive for testers; make sure you have a quiet place to do the testing; record the test results as soon after the test as possible; and, finally, analyze the test results and recommend redesigns to correct problems identified (Dickstein and Mills, 2000).

While people often equate usability assessment with this type of formal usability testing there are, in fact, other methods of measuring usability. Alternate approaches 
include inquiry and inspection (Battleson et al., 2001). The inquiry method is typically designed to gather information on users' experiences and preferences, and methods may include focus groups, interviews, surveys, self-reporting logs, and journaled sessions. The inspection method usually involves heuristic evaluation and cognitive walk-throughs and does not involve users. No matter what method is used, it should be part of a continual or iterative process of assessment and improvement (Head, 1999).

Usability testing does not need to be an expensive, time-consuming process. Meaningful and accurate results can be obtained with very few users. Nielsen (2000b) says as few as five is sufficient, while Krug (2000) maintains that as few as three or four users suffice, since the first few users are likely to encounter all of the most significant problems.

While there are many articles on usability testing of library web sites, very little is available on usability testing of online library instruction tutorials. A 1999 ACRL presentation discussed the usability testing of an online tutorial by the University of Minnesota, which used the inspection method involving heuristic evaluations and cognitive walkthroughs (Dickstein et al., 1999). In addition, the Bobst Library at New York University conducted usability testing on several of its online tutorials (Rohmann et al., 2002; Bobst Library, 2002). The approach adopted by the Bobst library involved formal usability testing, and informed the design and philosophy of the Wilfrid Laurier University Library usability evaluation project. A total of 15 students participated in testing and a monetary incentive was provided. Testing was carried out by three librarians, one to record comments, one to record paths students took and time taken to answer questions, and one to read a pre-prepared script and ask questions. The testing was performed over a period of less than one hour and a total of 16 questions were asked. Some questions required students to perform a particular task using the web tutorials. However, other questions asked students about their level of satisfaction or impressions of tutorial features such as navigation, design, overall look and feel, and the effectiveness of tutorials in reinforcing learning.

\section{Background}

In early 2001 Wilfrid Laurier University librarians started work on an online information literacy tutorial designed to focus on basic information literacy competencies for first year students. At the time of its launch in September 2001, the tutorial consisted of five modules:

(1) Defining your research topic.

(2) Information requirements.

(3) Searching for information.

(4) Searching the catalog.

(5) The internet.

In September 2002, an additional module on finding journal articles was added. Automatically graded online quizzes and a number of ungraded self-test exercises were built into the tutorial to help students practice concepts as they progressed. WebCT was used to deliver the tutorial during its first year of implementation. In the second year the tutorial was offered on the web, with only the quizzes delivered through webCT. During the first year 800 students in first year Communication Studies and 
Geography classes were required to complete the tutorial as part of their course work, and in its second year of delivery over 1,000 students took the tutorial. Typically, tutorial quizzes counted for 5 percent of the student's grade for the course in which it was integrated.

Evaluation tools were developed to gauge student satisfaction, gather impressions of the tutorial as a learning experience, and to determine evidence of actual student learning. Methods used included a student questionnaire, a pre-test/post-test, graded quizzes, and usability testing. Although the pre-test and post-test evaluations indicated significant progress in many information literacy competencies, student questionnaires identified some problems with the tutorial. This article will focus on the usability testing component of the tutorial evaluation, which was planned to help address these problems. The problems we wished to address are outlined in addition to the methods used, the results obtained, and how results were used to inform a tutorial redesign project which occurred in the summer before the tutorial was launched for a second year. Student satisfaction with the tutorial revisions inspired by the usability testing are also discussed.

\section{Problems and goals}

Student evaluation questionnaires, quiz results, staff testing and observations gathered during the tutorial's first year identified several problems areas. Basic navigation and tutorial design appeared to be intuitive but there were some concerns about links, pop-up windows, the location of the Ask Us link, and the ease of use of practice exercises and quizzes. Students commented that the presentation of information was too text-based making tutorial progress boring or arduous at times. Issues with WebCT surfaced, including some student confusion with the signing in process, occasional scripting errors, and slow loading of pages. Student questionnaire responses indicated that the tutorial was too long and too repetitious, that there was too much detail in certain modules and that some explanations were too ambiguous or unclear while others were too basic. The consistently low quiz scores for certain questions also pointed out the need for better explanations of some concepts.

These evaluation results were useful in pointing out that problems existed, but did not provide enough information to help identify which specific areas needed changes. Therefore, we chose to do usability testing to provide additional detail on the problems which had been identified through other evaluation methods. We recognized that usability is multi-faceted, and therefore to be truly usable Laurier Library's information literacy tutorial needed to meet multiple goals. Usability testing, therefore, was intended to help determine how appropriate or effective the following tutorial elements were for users:

- Navigation: how easy is the tutorial to navigate (including moving backwards and forwards, links to external pages, etc)?

- Design: is page design appealing and effective or are there improvements needed?

- Layout and presentation of information: does the right balance exist between text and non-textual information; is layout of information on pages conducive to effective learning? 
- Interactivity: is interactivity effective; is there an appropriate amount of interactivity or could some be added; if so, where would it be most useful?

- Use of language: is language pitched at the right level, is it clear or obtuse, is the tone right?

- Content: is tutorial content too common-sense or too advanced; is information felt to be relevant by students; is there too much detail or length and if so where; is there unnecessary repetition and if so where; what useful information did students learn, and what did they know already; which were the best and worst modules?

- Tests: were self-test exercises and quizzes clear, reasonable and helpful?

In addition, we hoped to identify other potential tutorial problems which had not previously been identified through other evaluation methods.

\section{Methodology}

The works of well-known experts such as Nielsen (1993, 2000a, 2000b) and Krug (2000) influenced the usability testing approach we adopted at Wilfrid Laurier University Library. Articles written about testing of library web sites also provided some inspiration, but their usefulness was limited because of the difference in context. An online library tutorial is used in a different way than a library web site. Library web sites are places users visit to obtain information or to access services, and therefore need to be very task-focused. A library web site functions as a gateway to many different kinds of information by offering logical paths through a myriad of resources, and it is important that information can be easily scanned and searched. Users will not necessarily move through information in a linear way but instead jump from one area of a site to another and may explore a number of different pathways within the site during any one visit. In contrast, the focus of a library instructional tutorial is to teach and its goal is effective learning. Students will typically need to sit and concentrate for a relatively long period of time (3-5 hours in the case of Laurier's tutorial). While interactivity is a desirable component of online instruction, students still tend to move through the tutorial information in a relatively linear and sequential fashion. Users need to approach a tutorial with patience and attention, and a tutorial is typically less finite and task oriented than a library web site. In addition, our goals for usability testing were multi-faceted and included areas like analysis of content that are often not evaluated in library web site usability tests. Having reflected on these key differences it became clear that we needed to plan our online tutorial usability testing using a different set of assumptions and definitions than we would have used for a typical library web site usability analysis.

In many respects, the Laurier Library's online tutorial usability testing followed fundamental principles common to most web site usability assessment. A low-tech, low-budget testing design was adopted using the principle that valid results can be obtained with a small number of users (Krug, 2000). Tests were conducted in an office with a desk, chair and computer with internet access. A total of four students took part in the usability testing. Care was taken to ensure that the testers were representative of the tutorial's target population: students needed to be either first or second year undergraduates with little or no library use experience or instruction. We posted advertisements for participants around campus offering the hourly wage for student 
employees in the library as compensation for the testers. This financial incentive was necessary since the tutorial was long (about five hours) and volunteers would therefore be difficult to attract. Testing occurred in January, a time of year when students are not too busy. Advertisements were very successful and more students applied than were needed for the testing, which allowed us to select participants who met the criteria for representing the tutorial's target population.

Two librarians conducted the testing. We introduced student participants to the goals and methods of the testing following a standard prepared script. Students then completed a very brief written questionnaire asking them about their year and course of study, their experience with the web and with the Laurier Library web site, and about any previous library instruction. For the major component of the usability test, students were asked to work through all tutorial modules and associated quizzes and to answer a standardized set of questions related to the completion of these tasks as they progressed. While students were required to complete the whole tutorial as part of the testing process, they did so in two or three sessions of between one and two hours each to keep the individual sessions relatively short. After students had completed the tutorial they were asked a set of summary questions. The results obtained were analyzed, conclusions were drawn, and recommended tutorial revisions were compiled.

However, given the differences already mentioned between traditional web site usability testing and testing for an online tutorial, some modifications to the traditional approach were necessary to achieve test goals. Librarians did not follow the traditional pattern of requesting students to perform tasks, then observing and taking notes throughout the entire testing session. Instead, this pattern was followed only in the beginning and end sections of each session. At the beginning, students were introduced to the test goals and process through a pre-prepared script, then a few navigation related questions were asked in person by a librarian who observed and noted student responses and actions. At the end of each session librarians conducted an informal brief interview to give students the opportunity to make general comments or share impressions which might not have surfaced from the scripted questions. Otherwise, students were given a standard list of questions as a handout, were asked to answer these questions while working their way through the tutorial, and were left on their own to do so.

This method of testing clearly placed a strong onus on the student to do the recording and therefore has much in common with the inquiry method of usability testing using journals or self-reporting logs (Hom, 1998). Because of the method we chose, many of the questions asked were designed to determine students' impressions or levels of satisfaction with areas of the tutorial design, navigation and content as opposed to determining their level of efficiency or success in carrying out specified tasks. The results obtained were, therefore, based largely on what students said rather than observations of what they did. This approach was felt to be practical and necessary for a number of reasons. To evaluate usability effectively it was crucial that all students work through the entire tutorial, which took on average five hours to complete. To obtain detailed and specific answers, it was important that students answer questions as they were in the process of interacting with the tutorial rather than letting a period of time elapse. Resource and personnel limitations meant that librarian testers simply could not give up this number of hours to sit with each student, observe them, and ask them all questions in person. Even if it had been possible, 
librarians felt that students could perceive five hours of close observation as onerous or intimidating. Using this mix of formal and inquiry methods of usability testing, librarians were able to observe some aspects of student action, but students were also able to complete most of the tutorial and quizzes in a more relaxed fashion on their own, knowing that a librarian was close at hand if they had any questions or ran into difficulties.

\section{Results}

The results obtained from the usability evaluation exercise were extremely useful and insightful. All students applied themselves diligently to the tasks assigned and provided excellent notes documenting their experiences, impressions, and opinions on many different aspects of usability as they interacted with the tutorial. The student evaluation questionnaires filled in by some 300 students during Fall term 2001, had provided general information on the tutorial's strengths and weaknesses. Usability testing allowed librarians to define the nature of existing problems far more precisely. For example, while the evaluations made clear that the tutorial was too long, the usability testing allowed librarians to determine which modules or sections of modules were too lengthy and which sections were not. More specifically, usability testing of the tutorial resulted in the following findings related to the test goals:

(1) Navigation. While tutorial navigation was felt to be generally intuitive and students found it easy to find key tutorial elements or to move backwards and forwards, they did identify some problems:

- Links - these were too numerous or confusing in some parts of the tutorial. It was suggested that all key tutorial content should be built directly in to page text rather than being introduced through internal linking, and lists of links should be especially avoided. In this way users would not miss important content. It was suggested that less extensive use be made of external links in particular, since students did not know whether visiting these external links was mandatory or not. It was suggested that it be made clear to the user that links are used as examples but that the external sites themselves do not have to be read in depth.

- Moving backwards and forwards - students commented that where interactive image maps or links were used it was sometimes unclear whether to click on a link or use the next button to proceed.

- Progress cues - it would be useful to have some cues to progress through each tutorial module. This could be achieved by using a menu displayed at all times showing the table of contents for the module and highlighting the section the user had reached.

- WebCT errors - when the user clicks on a tutorial link in WebCT a pop-up window typically appears. In some cases a link to an external site would open up in the same window rather than a new window, due to a WebCT bug. This introduced an inconsistency in navigation and was confusing to users.

(2) Design. Suggestions for improvement to the tutorial's visual appeal included introducing more graphics and color in certain areas. 
(3) Layout and presentation of information. Many pages were too text-based, making it hard for students to concentrate and absorb information. Suggestions included introducing more point form, more chunking, and less reliance on descriptive paragraphs and long pages of text.

(4) Interactivity. Students responded very favorably to the instructional module on the library catalog which was interactive and made extensive use of clickable image maps to teach steps in searching and retrieving items by progressing through a series of interactive exercises. There was consensus that this approach helped hold student attention and also reinforced important skills by applying a hands-on approach, and students requested that more modules use this interactive approach.

(5) Content:

- Some specific content was identified as too basic or obvious including parts of the two introductory modules and some of the general internet searching tips in the final module.

- A few tutorial areas, such as the section on Boolean searching, were identified as being confusing or insufficiently explained.

- Tutorial content was identified as being too lengthy in places, especially in the searching for information module, and to a lesser extent in the library catalog module. Other content was identified as unnecessarily repetitive.

(6) Use of language. Writing tone and style were generally found to be effective though in one area the language was felt to have the effect of "dumbing-down" and excessive use of library jargon was felt to be problematic in the third module.

(7) Tests:

- WebCT quizzes were easy to use though the standard WebCT quiz instruction page was found to be confusing. Students found quiz questions unreasonably difficult in the library catalog module (student quiz results in the previous year were very low in this module, confirming student test observations). Students commented that the quiz exercises should involve more hands-on tasks, especially in modules which lend themselves well to this such as the library catalog module.

- Ungraded self-test exercises (primarily multiple choice in format) were identified as being a very effective way of reinforcing concepts and skills and more extensive use was recommended.

In addition to providing invaluable information on the effectiveness of the tutorial elements outlined in the original test goals, the usability testing allowed librarians to gather information and identify problem areas not found through other assessment methods. For example, student test participants identified content which they felt was missing from the tutorial and would be helpful to include, like a virtual map or tour of the library building. Librarians also discovered which specific concepts in the tutorial were already known by students and which were not, as well as what information the students themselves saw as the most important and useful in each tutorial module. 


\section{Tutorial redesign}

These results guided an extensive overhaul of the Laurier Library's Research Skills tutorial done in summer 2002 and completed for use during the 2002/2003 academic year. Librarians were responsible for editing and revising tutorial content, while changes in web design and programming or scripting necessary to achieve recommended changes were done by a computer science student hired for three months over the summer.

Most of the changes suggested through usability testing were implemented. Navigation was made more consistent and clear in the areas which had caused confusion during testing, and the number of links was reduced by incorporating more tutorial content into the main pages and reducing external links. The tutorial was made less text-intensive, with more emphasis on presenting information in small chunks of text or using bullet form, with bolding of key terms for easier reading. Tables were introduced extensively to improve ease of scanning. In an effort to improve design, more color was added through colored fonts and bullets and more graphics were introduced. More interactivity was added through the use of clickable image maps to facilitate a learning-by-doing process in the library catalog and journal article modules. Tutorial content was shortened considerably by cutting out sections which students had identified as too basic or which they knew about already; wording was tightened up, the number of examples was reduced, and descriptions identified as confusing or jargon intensive were simplified. Explanations were expanded in areas which had been identified as inadequate, an additional module on finding journal articles was added, and the internet module was revised extensively to shorten areas which had been identified as too basic (such as the section on searching the internet, which students consistently identified as something they already knew) and to expand sections on how to evaluate internet content, which students found useful. A virtual tour of the library, which had been requested by student testers, was also added. Despite these additions, the overall tutorial length was significantly shorter than the previous version due to overall cuts and changes identified in the usability testing process.

One major decision was to move tutorial content from WebCT to the library's web site. Although there were many reasons for this change, including a desire to make the tutorial fully accessible to users with visual impairments, usability testing did influence the decision. Testers had identified a number of scripting errors experienced in WebCT which caused confusion. Moreover, we wanted more flexibility in the design of the tutorial: WebCT at Laurier essentially only allowed us to customize the centre screen while the top and left hand menus allowed very little customization and yet took up large amounts of space. Some feature changes identified through usability testing, such as a context-sensitive left menu which presents the table of contents for each module, allowing users to see where they are in the module and monitor their progress, were not possible in WebCT.

Testing was also considerably reworked as a result of the usability findings. Interactive practice exercises were introduced extensively at the point of relevance throughout the tutorial. Graded quizzes were the only tutorial feature maintained in WebCT, because of the automatic grading feature and easy statistical analysis offered, but quizzes were significantly reworked. Many questions were reworded to enhance clarity and reflect revised tutorial content. Previously, quizzes had emphasized facts and knowledge rather than the ability to apply a skill. Wherever feasible, new 
questions were designed to involve hands-on exercises geared to evaluate the students' ability to apply core skills and concepts. For example, students are now required to search the library's catalog and journal indexes and to visit specified web sites in order to answer questions.

\section{So, is it working now?}

We are in no doubt that tutorial revisions inspired by usability testing results have led to improved effectiveness of the Laurier Library tutorial. The Library also conducted further evaluations of the revised tutorial during the 2002/2003 academic year, when a thousand students took the tutorial as a component of one of their courses. A student evaluation questionnaire completed by a majority of these students provides some insights on the effectiveness of tutorial revisions. Questionnaire responses definitely indicate that the tutorial has improved. Problems which surfaced with the older version of the tutorial are not surfacing again or receive much less emphasis. In particular:

- The number of students commenting that they would not change anything about the tutorial or that they felt they benefited from it is much larger than the previous year.

- Length is clearly no longer a significant problem, with students saying that the tutorial now takes them 3.5 hours on average to complete, more than an hour less than the previous year, and significantly fewer complain about tutorial length.

- Students do not report on any major problems with navigation, design, or presentation of information.

- Positive comments were made about interactive tutorial elements, especially practice exercises, but a few students comment that interactivity should be yet further enhanced.

- Quizzes seem improved based on quiz results though some problems still persist with a few questions, and students comment that better instructions are needed on the quizzes. Quiz instructions are partly a problem due to WebCT's default quiz instruction page.

- We recognize that assessment, including usability testing, needs to be an ongoing process to ensure continued effectiveness of the information literacy tutorial. Usability testing should be conducted again to further validate findings and offer additional results.

\section{Conclusion}

The value of conducting usability testing of an online information literacy tutorial cannot be underestimated. Even where such testing is modest in approach it can go a long way to improving the effectiveness of instruction and can form a core component in a wider assessment plan. Our method of usability evaluation provided detailed insights on ease of use of Laurier Library's instructional tutorial, as well as users' level of satisfaction with both the design and content of the tutorial. Many creative ideas surfaced from participating testers, and this form of evaluation provided information which other assessment techniques did not. Usability testing provided justification for revisions to the tutorial which resulted in a much-improved learning tool demonstrating a higher level of responsiveness to both user needs and behaviors. 


\section{References}

Battleson, B., Booth, A. and Weintrop, J. (2001), "Usability testing of an academic library web site: a case study", The Journal of Academic Librarianship, Vol. 27 No. 3, pp. 188-98.

Bobst Library (2002), "Usability testing at Bobst Library at New York University", Bobst Library, New York University, New York, NY, available at: www.nyu.edu/library/ resources/usability/testing1.htm

Carter, E.W. (2002), "Doing the best you can with what you have: lessons learned from outcomes assessment", The Journal of Academic Librarianship, Vol. 28 No. 1, pp. 36-41.

Dewald, N.H. (1999), "Web-based library instruction: what is good pedagogy?", Information Technology and Libraries, Vol. 18 No. 1, pp. 26-31.

Dickstein, R. and Mills, V. (2000), "Usability testing at the University of Arizona Library: how to let users in on the design", Information Technology and Libraries, Vol. 19 No. 3, pp. 144-51.

Dickstein, R., Loomis, A. and Veldorf, J. (1999), "The user is the expert: experiences at three universities using usability studies to inform gateway and tutorial web designs", paper presented at ACRL 9th National Conference, Detroit, MI, April 8-11, available at: www.tc.umn.edu/ jveldof/ACRL99/userdesign.html

Gore, P. and Hirsh, S.G. (2003), "Planning your way to a more usable web site", Online, Vol. 27 No. 3 , pp. 20-7.

Head, A.J. (1999), "Web redemption and the promise of usability", Online, Vol. 23 No. 6, pp. 20-3.

Hom, J. (1998), "The usability methods toolbox", available at: www.best.com/ jthom/usability

Krug, S. (2000), Don't Make Me Think: A Common-Sense Approach to Web Usability, New Riders Publishing, Indianapolis, IN.

Nielsen, J. (1993), Usability Testing, Academic Press, Boston, MA.

Nielsen, J. (2000a), Designing Web Usability, New Riders Publishing, Indianapolis, IN.

Nielsen, J. (2000b), "Why you only need to test with five users", AlertBox: Current Issues in Web Usability, March 19, available at: www.useit.com/alertbox/20000319.html

Rohmann, G., Tempelman-Kluit, M. and Pavelse, M.J. (2002), "Web usability testing: three cases from the NYU Libraries", Connect: Information Technology at NYU, Spring, available at: www.nyu.edu/its/pubs/connect/archives/index02.html\#spring

\section{Further reading}

Bober, C., Poulin, S. and Vileno, L. (1995), "Evaluating library instruction in academic libraries: a critical review of the literature 1980-1993", The Reference Librarian, No. 5152, pp. 195-202.

\section{Appendix: Self-reporting log questions for testers \\ Questions asked about each module \\ Part A: Navigation/usability evaluation}

(1) Was it always clear to you how you should move forward/back in the module to get where you wanted to go? If not, please elaborate.

(2) Were the links in this module straightforward or confusing? If you found them confusing, please tell us why.

(3) Do you think that there were too many links in this module?

(4) Did you find scrolling a problem/frustration at any point in this module? If yes, please explain where. 
(5) Did you find the various practice exercises contained in this module easy to follow?

(6) Are there any other navigation/usability issues or problems in this module?

\section{Part B: Content evaluation}

(1) Is there any place in this module where you feel "why does this matter" or "why are they telling me this?" If so, where?

(2) Is this module too long, the right length, not long enough (needs more explanation?) If it is too long, what could be cut?

(3) What are the most important parts of this module?

(4) Was there anything in this module that you already knew? If so, what?

(5) Was there any content in this module that was not explained well? If so, what?

(6) Is there anything in this module that you felt was too basic? If so, what?

(7) Is there anything in this module that you felt was too complicated or confusing? If so, what?

(8) Did you feel that the writing style and tone of the module was appropriate? Why or why not?

(9) Was the content in this module presented effectively for learning? Why or why not?

(10) Did you feel at any point that this module was too long or too boring, or you felt your attention drifting? If so, where?

(11) Were the quiz questions reasonable?

(12) Were the practice exercises helpful? Why or why not?

(13) What would you suggest to improve this module?

\section{Overall tutorial questions}

(1) Do the modules progress logically?

(2) Is there any obvious repetition between modules or within modules?

(3) Which modules did you think were best? Why?

(4) Which modules did you think were worst? Why?

(5) What would you suggest to improve the content of this tutorial?

(6) What would you suggest to improve the usability of this tutorial (e.g. navigation, ease of use)? 